\title{
Experimental evaluation of a concrete core slab with phase change materials for cooling purposes
}

\author{
Lidia Navarro $^{1}$, Alvaro de Gracia ${ }^{2}$, Albert Castell ${ }^{1}$, Luisa F. Cabeza ${ }^{1^{*}}$ \\ ${ }^{1}$ GREA Innovació Concurrent, Universitat de Lleida, Edifici CREA, Pere de Cabrera s/n, 25001, Lleida, \\ Spain. Tel: +34.973.00.35.77. Email: lcabeza@diei.udl.cat \\ ${ }^{2}$ CELiMIN, Universidad de Antofagasta, Campus Coloso, Av. Universidad de Antofagasta, 02800 \\ Antofagasta, Chile
}

\begin{abstract}
Due to the high amount of energy consumed by the building sector, efforts need to focus not only on improving the building envelope but also on enhancing the energy efficiency of HVAC systems. In this study, an innovative technology for cooling application in buildings is evaluated. A prefabricated concrete slab incorporating phase change material (PCM) was used as internal separation in the active slab cubicle. The incorporated PCM is paraffin macro-encapsulated in aluminium tubes. The target is to use the internal slab as storage unit and as an active cooling supply to replace totally or partially conventional HVAC systems. The operational mode consists of solidifying the PCM with the outside cold air (below solidification temperature) during the night time for covering a later cooling demand. Experimental analysis shows the energy performance of the technology, as well as a comparison with a conventional cooling system.
\end{abstract}

Keywords: thermal energy storage (TES), phase change materials (PCM), concrete core slab, building, space cooling

\section{Introduction}

The high energy consumption rate that belongs to the building sector (40\% of global energy consumed in Europe) is mainly attributed to the heating, ventilating, and air conditioning systems (HVAC). Moreover, the comfort parameters are getting stricter, especially under summer conditions. In the recent years a rise in the number of installed air-conditioning systems has been observed, resulting in peak load problems, increasing the electricity cost and affecting the energy balance [1]. The European directive on the energy performance of buildings (EPBD) promotes the inclusion of very low and close to zero energy buildings, as well as the use of renewable energies. Hence, it is critical to reduce the energy consumption of the building, especially during peak load periods.

Within this situation solar energy systems [2] and thermal energy storage [3,4] among others, are topics widely studied in the research field to achieve low energy rates in buildings. Passive strategies focused on reducing the energy demand such as thermal 
insulation, thermal mass, seasonal shadings or blinds are extensively incorporated in the building design process [5].

On the other hand, new active systems such as renewable energy facilities (i.e. photovoltaic, solar thermal) or HVAC systems coupled to renewable energies are still difficult to be included by architects and engineers in the buildings designs [6]. One of the main reasons of this barrier is the difficulties that present these new technologies for their integration in the building design [7], which limits strongly their promotion as an alternative to conventional systems.

Moreover, most renewable energies require of a storage system in order to overcome the mismatch between the production and the supply and hence, to increase their energy efficiency [8]. Many research has been done in this field, usually implying an additional storage volume that makes the integration of the system in the building even more difficult $[7,9]$. To overcome such problem, phase change materials (PCM) can play an important role, especially in some applications such as domestic hot water tanks or the increase of thermal inertia in building envelopes [10,11], by means of enhancing the heat storage capacity with a limited increase of the volume.

Heretofore, this issue has not been widely considered although some studies applied the constructive incorporation of their thermal storage systems. The TermoDeck system [12] and the thermally activated building systems [13] are some examples of these alternative systems. The common property of these systems is the active charge of a building component (wall, floor, and ceiling) for a later passive discharge which gives stable comfort conditions to the building.

The novelty of the system presented in this paper is the inclusion of phase change materials (PCM) inside a building component, which is used as a storage unit and a cooling supply. Thereby, thermal energy is stored and released inside the building comfort temperature range [14]. The new technology presented is designed to cover, completely or partially, the cooling demand through an active charge and discharge of the storage unit. With this system, the thermal storage is fully integrated in the building, making use of a dead volume.

The design parameters and required conditions were studied in a previous study [15], in order to determine if the proposed system would be able to operate under both summer and winter conditions. Since then potential of the active slab to store and provide heating and cooling was demonstrated a complete experimental summer season campaign is presented in this paper.

The aim of this paper is to evaluate the real behaviour of the prototype for cooling purposes by testing different control strategies to maximize the benefits of using the active slab. Moreover, the active slab is evaluated when operating coupled to a real demand cubicle and compared to a conventional cooling system. 
10

\section{Experimental set-up}

The experimental set-up at Puigverd de Lleida (Spain) allocates two house-like cubicles with internal dimensions of $2.4 \times 2.4 \times 5.1 \mathrm{~m}$ and a constructive system based on alveolar bricks is used to perform this experimentation. The only difference between these two cubicles is that one of them has a conventional slab (reference) and the other one an active slab (active slab). The active slab consisted of a prefabricated concrete slab with phase change materials inside its hollows (Figure 1). The slab system will be acting in the first floor considering negligible the heat flux towards the second floor.

Moreover, both cubicles are instrumented with several sensors registering data every 5 min interval:

- Internal surface temperature of walls, roof and floor (Pt-100 DIN B calibrated with a maximum error of $\pm 0.3^{\circ} \mathrm{C}$ ).

- Inside temperature and humidity (ELEKTRONIK EE21 with an accuracy of $\pm 2 \%$ ).

- External temperature and humidity (ELEKTRONIK EE21 with an accuracy of \pm 2\%).

- Solar irradiance, horizontal and vertical (Middleton Solar pyranometers SK08 \pm 2 $\left.\mathrm{W} \cdot \mathrm{m}^{-2}\right)$.

- Wind speed and direction (DNA 024 anemometer).

(1)
Figure 1. Active slab cubicle in experimental installation at Puigverd de Lleida and 3D scheme.

\subsection{Prototype description}

The prototype consisted of a prefabricated concrete slab which is widely used as commercial element in new and existing buildings. The component has a thickness of $30 \mathrm{~cm}$, with a surface of $2.4 \mathrm{~m} \times 2.4 \mathrm{~m}$ and it is formed by 14 channels where the PCM is located. A hole at the beginning and end of each channel allows the air flow through the slab. Moreover, under these holes an air duct installation is implemented with 6 
gates (Madel CTM-AN 250x200 mm) and a fan (Sodeca CMP-512-2M) of $80 \mathrm{~W}$, which permits different operational modes (Figure 2). The fan can operate under different air flow velocities and during these experiments the air flow rate measured was $0.066 \mathrm{~m}^{3} / \mathrm{s}$. Moreover, a solar air collector with a surface of $1.3 \mathrm{~m}^{2}$ and a power rating of $1330 \mathrm{Wp}$ (AIRSOL-20), which integrates a fan connected to a photovoltaic panel is implemented in the south facade as a heat supply for the winter mode, and it is coupled to the rest of the active system. Thus, the air can be taken and blown from indoors, outdoors or from the solar air collector, depending on the used operational mode. In this paper authors presented experiments under summer conditions.

The whole system is instrumented by 20 sensors measuring at different strategic points of the slab with the purpose of analysing and characterizing the technology:

- PCM temperatures at different locations inserted inside the aluminium tubes (Pt-100 $1 / 5$ DIN B calibrated with a maximum error of $\pm 0.3^{\circ} \mathrm{C}$ ).

- Air temperature and velocity at the inlet and outlet of the slab (KIMO CTV210 with an accuracy of $\pm 0.03 \mathrm{~m} / \mathrm{s}$ and $\pm 0.25^{\circ} \mathrm{C}$ ).

This technology is equipped with a control system that allows the active slab to operate depending on the weather conditions and the energy requirements of the cubicle. Six of the temperature sensors mentioned before are used in the control system. Two of them are measuring the PCM temperature at inlet and outlet of the slab (PCM inlet, PCM outlet), and two more temperature sensors located at the inlet and outlet part of the air duct installation registering air temperature (Tinlet, Toutlet). The location of these sensors is indicated in Figure 2. Moreover, internal ambient temperature, and outside temperature sensors are also used in the control system.

Moreover, both cubicles are equipped with two heat pumps (Fujitsu inverter ASHA07LCC), one for each floor, in order to maintain a certain set point temperature. In the active slab cubicle if the system is not able to cool down the internal ambient the heat pump is used as a support cooling supply, in order to provide temperature comfort levels. Therefore, the energy consumption of the heat pumps of both cubicles can be compared.

As it has been previously stated, the system has been designed both for heating and cooling. In order to ensure its suitability for both periods the selected PCM was RT-21 with a phase change temperature around $21{ }^{\circ} \mathrm{C}$. The phase change temperature of the PCM selected was studied in a previous article [15], concluding that it is an appropriate temperature for heating and cooling purposes in this application and under the weather conditions of the experimental facility. Moreover it is inside the comfort temperature range of buildings. In addition, authors selected the paraffin RT-21 as a phase change material because of its thermal properties, and also to avoid subcooling or hysteresis problems that salt hydrates may provide. 
PCM is macro-encapsulated in aluminium tubes of $12 \mathrm{~mm}$ diameter and $100 \mathrm{~mm}$ of height, which are fixed in wooden structures following criteria of heat transfer enhancement between the air and the PCM in cross-flow. The total number of tubes installed is 1456 that contain $52 \mathrm{~kg}$ of RT-21.

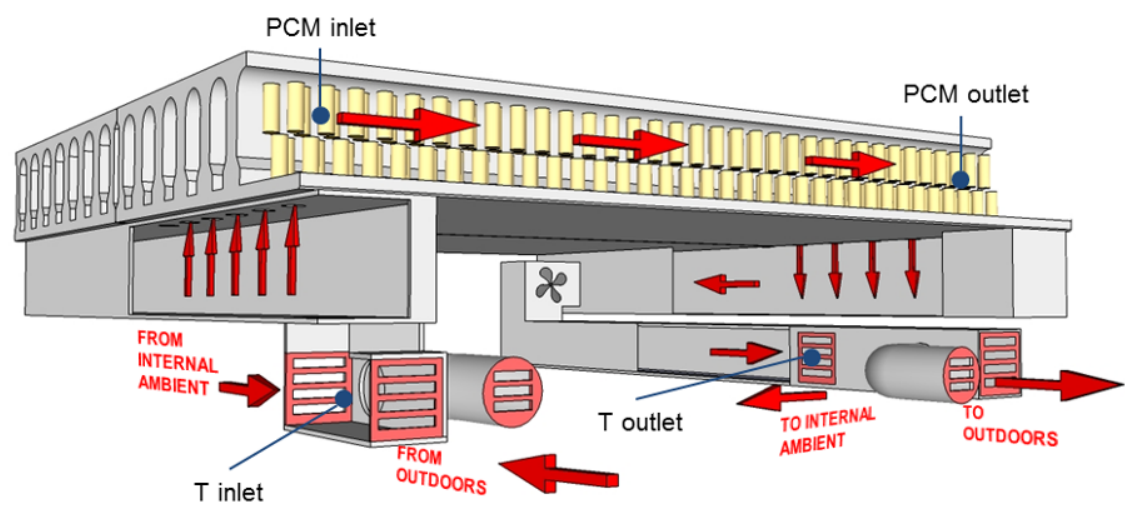

Figure 2. 3D scheme of the active slab system.

\subsection{Operating principle}

The active slab is used as a storage component and cooling supply for covering partially or totally the demand (depending on the weather and the energetic requirements). The operating principle of the concrete slab system during summer period is based on the night free cooling concept. Thereby, at night time, once outside temperature drops below the phase change temperature $\left(21^{\circ} \mathrm{C}\right)$, outdoor air is injected to the slab in order to solidify the PCM (Figure 3a). Moreover, during this period the system offers the possibility of a night free cooling mode (Figure $3 \mathrm{~b}$ ) if the internal ambient requires it. So, the outside air passes through the slab, keeping the solidification process on-going, and then it is pumped inside the cubicle to cool down the internal ambient. Once the PCM is completely solidified and there is no cooling demand, the system moves to the storage mode (Figure 3c). Finally, during the day, when there is a cooling demand, internal ambient air is pumped through the hollows of the slab, cooled down as a result of the heat exchange with the PCM, and pumped back into the cubicle (Figure 3d). 
a)

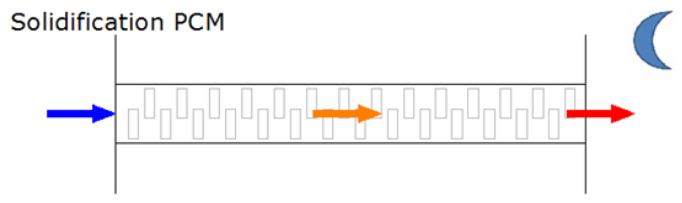

b)

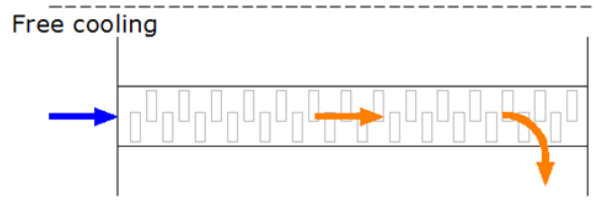

c) Storage

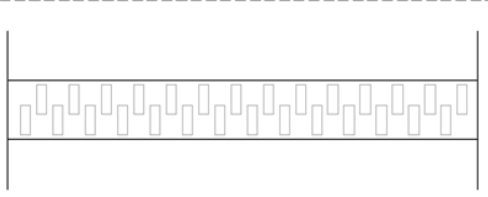

d) Melting PCM

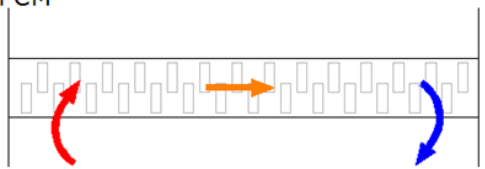

Figure 3. Schematic operating modes from the active slab in summer period.

\section{Methodology}

In this study a complete experimental campaign during summer season is presented. Weather conditions in the experimental facility location (Puigverd de Lleida, Spain) could be distinguished in mild and severe summer, as done in previous studies of active systems in the same facility [16]. This distinction is mainly done because the minimum temperatures at night should drop below $21{ }^{\circ} \mathrm{C}$ to solidify the PCM, which directly affects the thermal performance of the slab system. Hence, mild summer conditions when minimum temperatures during night time are suitable for PCM solidification (below $21^{\circ} \mathrm{C}$ ), while severe summer conditions occur when the temperature at night does not drop below $21{ }^{\circ} \mathrm{C}$. The active slab system was tested following different operation modes. Authors started the experimentation by programming the simplest mode and adding more complexity to the following ones by introducing more variables. In this way, the first experiment performed was the following one:

- Time schedule (TS); the active slab system is programmed following a time profile. The heat pump is fixed at $25{ }^{\circ} \mathrm{C}$ as set point temperature during all day in both the active slab and the reference cubicle. The charge and discharge schedule of the slab system was selected based on previous studies [15] and it is set as follows, while the rest of the day the system remains in storage mode:

$$
000 \mathrm{~h}-07 \mathrm{~h} \text { charge period. }
$$

o $11 \mathrm{~h}-18 \mathrm{~h}$ cold discharge period.

Next step was to test the temperature control system implemented in the active slab in order to optimize the use of the fan and to maximize the potential of the system when 


$$
Q_{\text {charge }}=A_{\text {duct }} \cdot C p_{\text {air }} \cdot \int_{t_{i . c h}}^{t_{\text {e.ch }}} \rho_{\text {air }} \cdot v_{\text {air }} \cdot\left(T_{\text {inlet }}-T_{\text {outlet }}\right) \cdot d t
$$

charging and discharging. The system performed depending on the outside conditions, the internal ambient temperature, and/or the PCM temperature. The tests programmed were the following ones:

- $\quad$ Cold storage (CS); at night time, the active slab system starts the charge period once the outside temperature is below the PCM temperature. During the day, once the internal ambient temperature is above the PCM temperature the cold discharge mode starts.

The active slab and the reference cubicle have the heat pump set at $25{ }^{\circ} \mathrm{C}$ during all day.

- $\quad$ Cold storage + Free Cooling ( $\mathrm{CS}+\mathrm{FC})$; this program follows the same pattern as the previous one in terms of starting the charge process. The difference is that once the charge period is started the night free cooling mode could be used if the cubicle has a cooling demand and the outside conditions are able to cover it.

As well as in the previous program the active slab and the reference cubicle have the heat pump set at $25^{\circ} \mathrm{C}$ during all day.

- Cold storage + Free cooling + Fans savings (CS+FC+FS); in this case the program follows the same pattern as the previous one, but some restrictions are added. During the charging period the system stops once the PCM is below its phase change temperature (when the PCM solidification is achieved) to limit the fan use. In addition, during the cold discharge period the slab system provides cooling supply until the internal ambient reaches a certain temperature by fixing a set point temperature of $24^{\circ} \mathrm{C}$.

As well as the other programs the heat pump of both cubicles was set at $25{ }^{\circ} \mathrm{C}$ during all day.

- $\quad$ Passive Discharge (PD); the charge process is done like in the previous cases at night-time with mechanical ventilation. However, the discharge process in this case is programmed passively, hence during daytime the fan and the gates will not work, staying at storage mode (see Figure 3c) until charge mode started again.

The energy consumption of the heat pumps installed in the active slab and the reference cubicle is registered by an electrical network analyser (Circutor MK-30-LCD). Therefore, the energy consumption of the heat pumps of both cubicles could be analysed and compared.

In order to quantify the amount of energy stored and released from the system, an energy balance is done with the experimental data. In Eq. (1) energy charged $\left(Q_{\text {charge }}\right)$ is defined by the energy injected in the slab during night-time. 
261 On the other hand, the discharged energy is the amount of energy used to cover the

262 cooling demand. It is distinguished between cold energy discharged ( $\left.Q_{\text {ColdDisch }}\right)$ defined in 263 Eq. (2) and free cooling energy ( $\left.Q_{\text {FreeCooling }}\right)$ described in Eq. (3).

$Q_{\text {ColdDisch }}=A_{\text {duct }} \cdot c p_{\text {air }} \cdot \int_{t_{\text {i.dis }}}^{t_{\text {edis }}} \rho_{\text {air }} \cdot v_{\text {air }} \cdot\left(T_{\text {outlet }}-T_{\text {inlet }}\right) \cdot d t$

$Q_{\text {FreeCooling }}=A_{\text {duct }} \cdot c p_{\text {air }} \cdot \int_{t_{\text {i.dis }}}^{t_{\text {edis }}} \rho_{\text {air }} \cdot v_{\text {air }} \cdot\left(T_{\text {inlet }}-T_{\text {outlet }}\right) \cdot d t$

$A_{\text {duct }}$ is the sectional area of the air duct, $C p_{\text {air }}$ is the air heat capacity, $\rho_{\text {air }}$ is the air density, $v_{\text {air }}$ is the air velocity. The inlet temperature to the slab is $T_{\text {inlet }}$ and the outlet temperature is represented in $T_{\text {outlet }}$. Temperature of the internal ambient of the cubicle is referred as $T_{\text {interior }}$.

\section{Results}

272

\subsection{Active slab summer potential}

As it is previously explained, the charging process of the active slab system during summer period consists of solidifying the PCM through the cold outside air during the night time. Hence, the system is dependent on the night temperatures which should be below the phase change $\left(21^{\circ} \mathrm{C}\right)$. However, in order to solidify the PCM the system needs high power rate which could be defined by a high temperature difference (Toutside - Tpcm).

In a previous paper, the authors presented a study of two parameters, the daily available power $\left(\mathrm{P}_{\text {available }}\right)$ and the daily required power $\left(\mathrm{P}_{\text {required }}\right)$, as a design tool for the active slab suitability [15]. It was demonstrated that climatic conditions in the experimental facility where the system is tested (Puigverd de Lleida, Spain) were suitable to solidify the PCM at least under mild summer conditions.

After the complete summer experimental campaign, the authors analysed the same parameters for the tests presented in this paper. Figure 4 shows the power available and required during the experiments performed in summer 2014. A clear difference could be distinguished between mild and severe conditions. In almost all the experiments under mild conditions the power required is completely covered, while under severe conditions there is not enough power available to solidify all the PCM implemented in the active slab. 


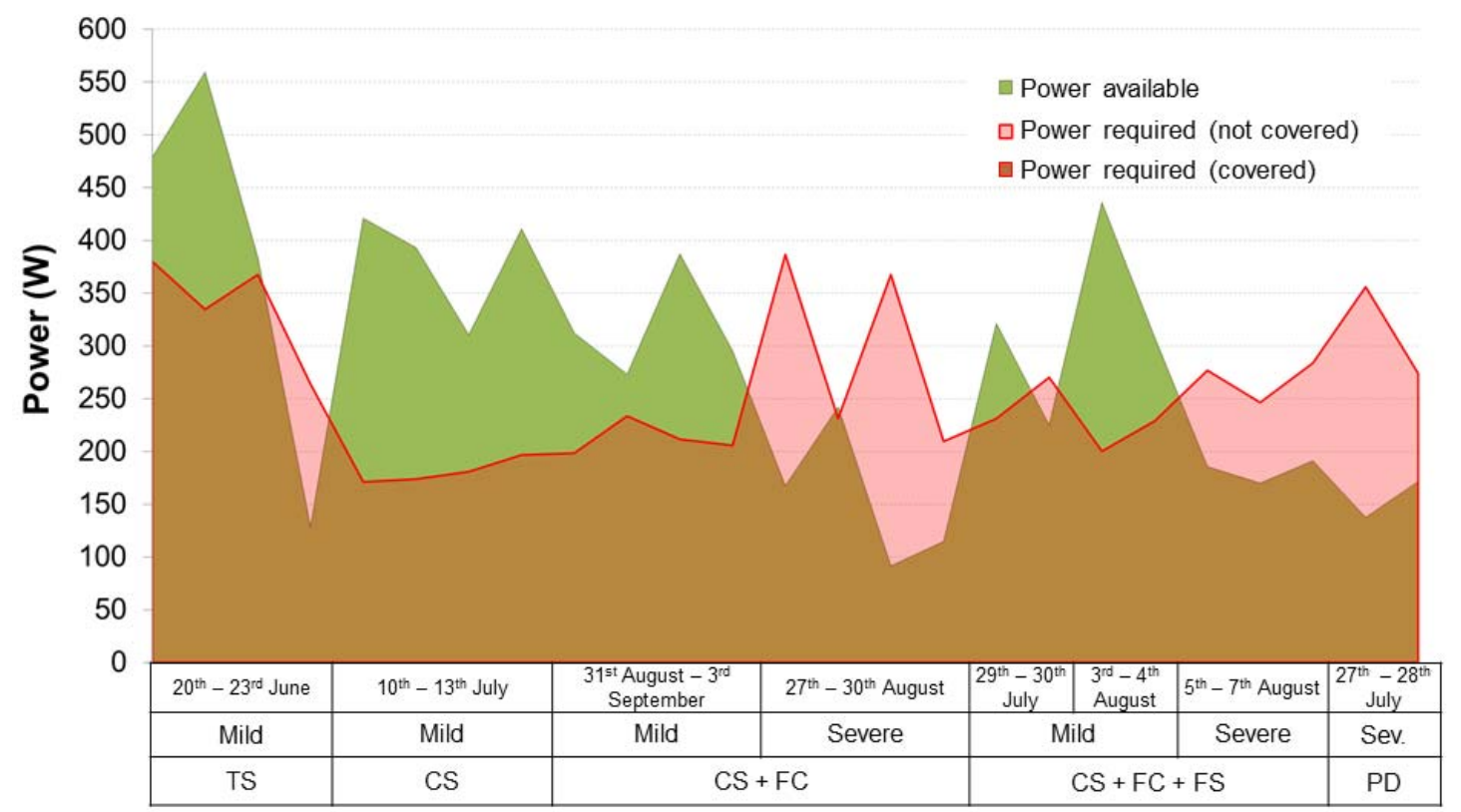

Figure 4. Power available and required to solidify the PCM of the active slab during the experiments presented for summer 2014.

\subsection{Time schedule experiments}

The experiments presented with this settings were performed from $20^{\text {th }}$ to $23^{\text {rd }}$ June 2014 under mild summer conditions, which means maximum and minimum mean outside temperatures around $31{ }^{\circ} \mathrm{C}$ and $14{ }^{\circ} \mathrm{C}$, respectively. Global solar irradiance peaks were of $1100 \mathrm{~W} / \mathrm{m}^{2}$. Figure 5 presents the temperature evolution during the four days of experiment. PCM temperatures are shown at the inlet and outlet part of the slab and different behaviour could be seen. While PCM located at the inlet part is fully cycled (melted and solidified) every day, the temperature of the PCM at the outlet is oscillating within the phase change range. Moreover, no differences were observed in the phase change temperature of the PCM during the solidification and melting processes after many cycles were carried on. 


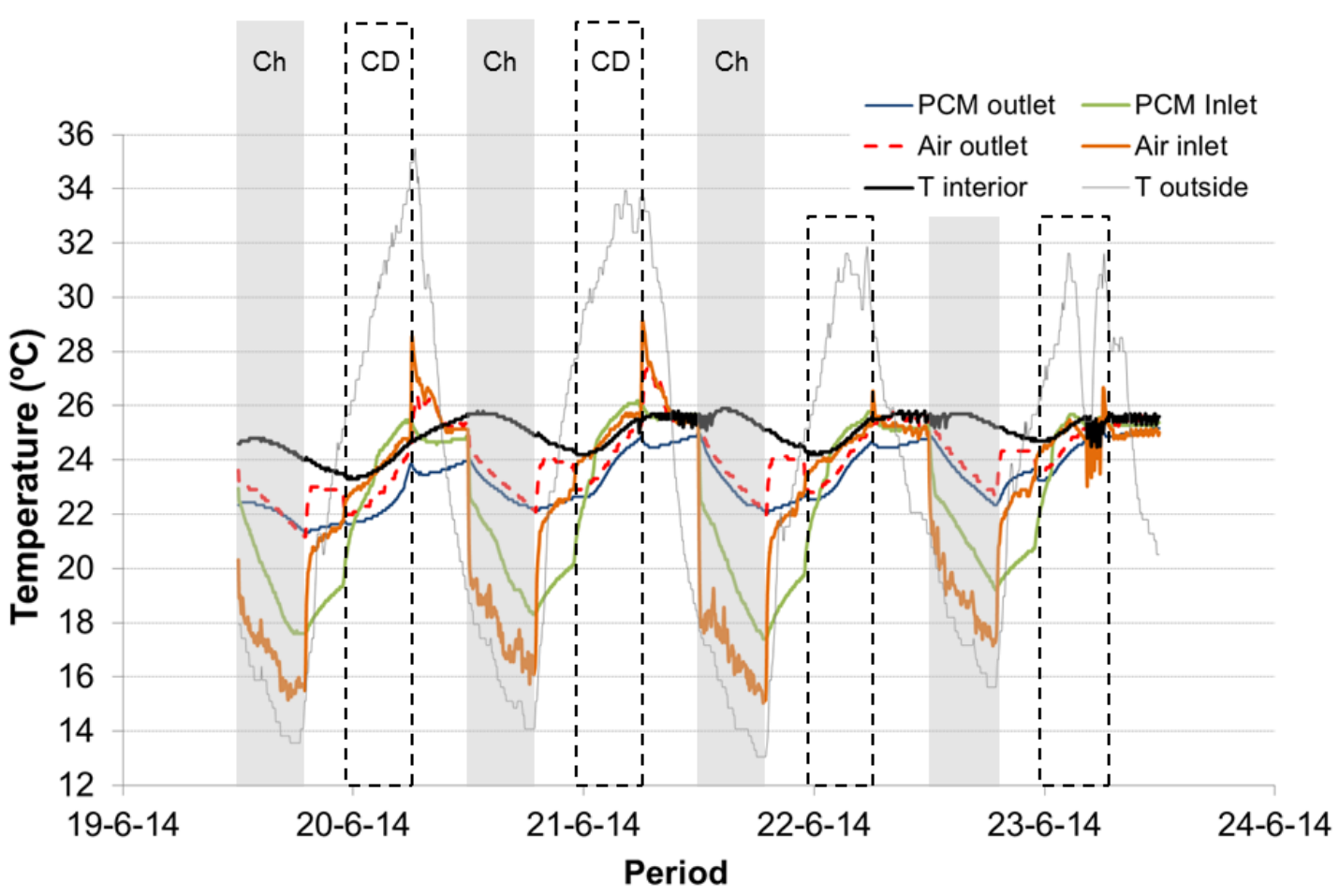

Figure 5. Time schedule experiment: temperature evolution of active slab cubicle during 4 days (Ch: charge period, CD: cold discharge period)

As it was previously explained this program does not take into account any temperature or comfort conditions. A time profile program was defined, wide enough to ensure the PCM solidification $(00 \mathrm{~h}-07 \mathrm{~h})$ and melting $(11 \mathrm{~h}-18 \mathrm{~h})$. The system is able to work successfully if a proper time profile is chosen. However, the active slab operation is not dependent on the temperature or energy requirements of the cubicle which may lead to negative effects. This can be seen in Figure 6, where the temperature evolution of the fourth day of experiment is presented in detail. The charge and cold discharge periods are shown as well as the period where the heat pump of the active slab cubicle is working to maintain the temperature set point of $25^{\circ} \mathrm{C}$. At the beginning of the charging period the heat pump is switched on. In order to optimize this situation, the active slab could have supplied free cooling while charging if the control system identifies that there is a cooling demand in the cubicle.

Moreover, at the end of the cold discharge process air outlet temperature surpassed 25 ${ }^{\circ} \mathrm{C}$, hence the system is not providing cooling anymore and the heat pump is switched on. In this situation the active slab is increasing the heat loads of the internal ambient. In addition, the heat pump is consuming more energy not just to maintain the comfort conditions but also to cool down the PCM with no purpose. (1) 


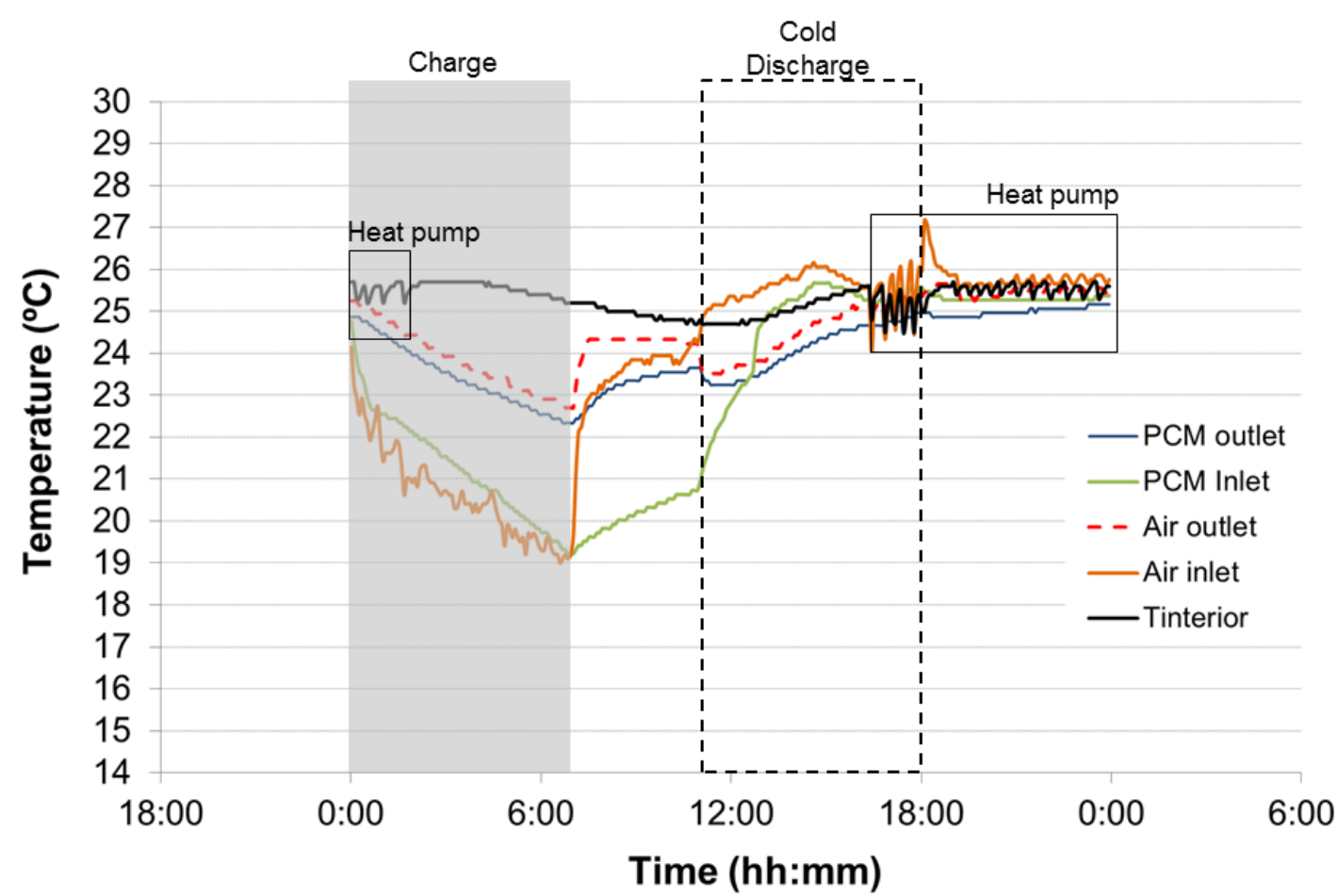

Figure 6. Time schedule experiment: temperature evolution of the fourth day of experiment.

\subsection{Control system experiments}

\section{- $\quad$ Cold storage (CS)}

First experiment tested with the control system was the cold storage (CS) one. Four consecutive days are presented, from $10^{\text {th }}$ to $13^{\text {th }}$ July, where the maximum and minimum outside temperatures oscillated between $31{ }^{\circ} \mathrm{C}$ and $12{ }^{\circ} \mathrm{C}$ respectively, representing mild summer conditions. Global solar horizontal irradiance during these days had peak measures around $1100 \mathrm{~W} / \mathrm{m}^{2}$.

Temperatures profiles of the experiment are presented in Figure 7, and the charge, discharge, and storage periods are also indicated. As expected, the behaviour of the PCM temperatures shows a faster response from PCM inlet to the cold air coming from outside ( $T$ inlet) during the charge period, than PCM outlet. Moreover, during the discharge period a similar behaviour is observed since PCM close to the inlet is heated up faster than PCM near the outlet.

During the cold discharge, the supplied air temperature (T outlet) started at $20{ }^{\circ} \mathrm{C}$ and reached a maximum of $23^{\circ} \mathrm{C}$. This contributed to keep the internal ambient temperature ( $\mathrm{T}$ interior) under $25{ }^{\circ} \mathrm{C}$ (set point temperature) during the four consecutive days and allowed not using the heat pump at all. Nevertheless, in the reference cubicle just the last day a cooling demand was needed due to the mild temperature conditions. For this 
reason, energy consumption values from the heat pump are not commented during this experiment.

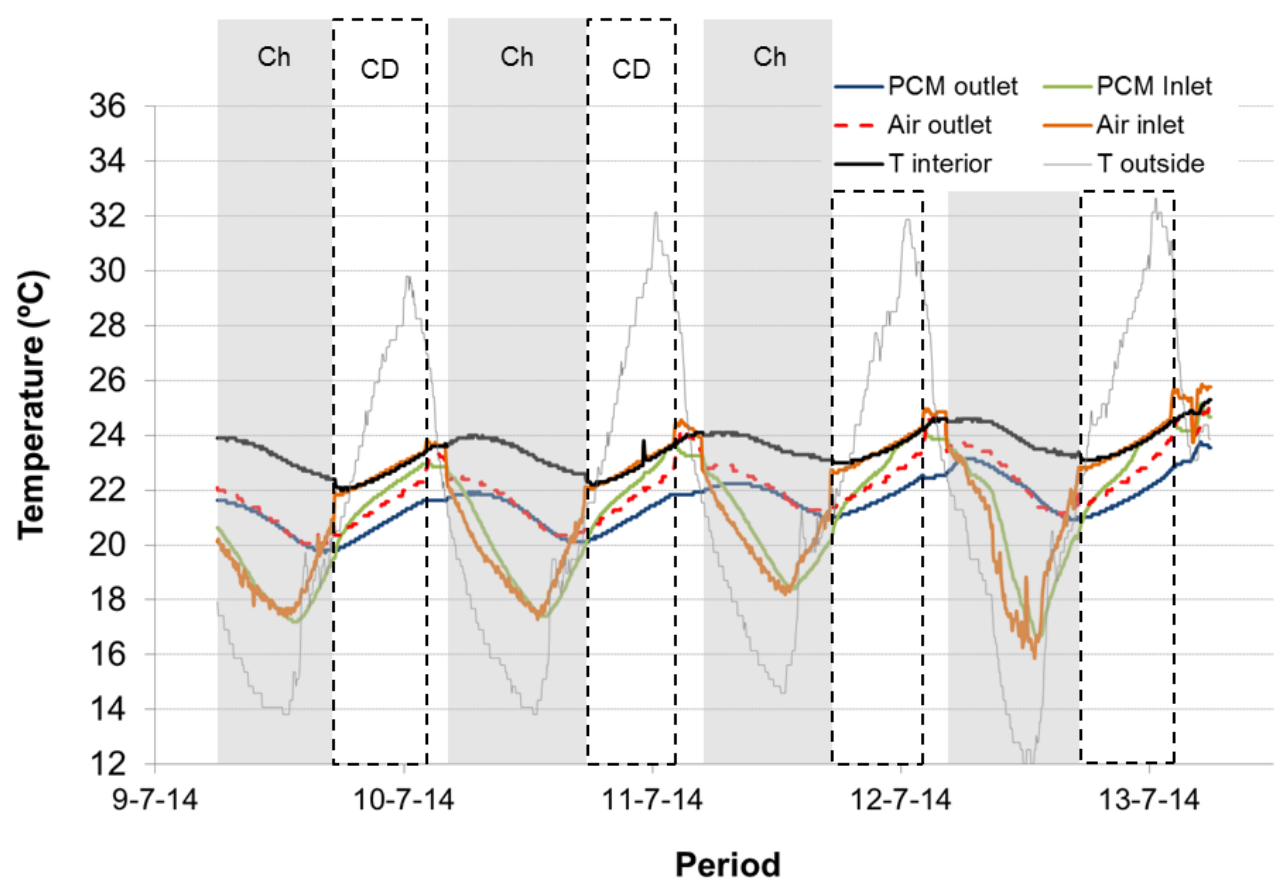

Figure 7. Cold Storage experiment; temperature evolution of active slab cubicle during 4 days (Ch: charge period, CD: cold discharge period).

In addition, notice that for this experiment, the system was operating most of the day (either for charge or discharge) which means the fan worked during almost $24 \mathrm{~h}$ a day and this contributed to a high electrical energy consumption of $2.8 \mathrm{kWh} /$ day.

\section{- Cold storage + Free cooling (CS+FC)}

Later on, a free cooling (FC) sequence was added to the program to take advantage from the outside cold air at night. The tests presented were performed form $27^{\text {th }}$ August to $3^{\text {rd }}$ September 2014. The first four days were evaluated as severe summer conditions with maximum outside temperatures around $34{ }^{\circ} \mathrm{C}$ and minimum outside temperatures above $19^{\circ} \mathrm{C}$. On the other hand, from $31^{\text {st }}$ August to $3^{\text {rd }}$ September maximum and minimum outside temperatures were $32{ }^{\circ} \mathrm{C}$ and $16{ }^{\circ} \mathrm{C}$, respectively, having mild summer conditions. During this experiment were registered solar maximum irradiance peaks of $900 \mathrm{~W} / \mathrm{m}^{2}$ the first four days and $1000 \mathrm{~W} / \mathrm{m}^{2}$ the last days.

Figure 8 shows the energy charged and discharged in the active slab as well as the energy that provided the free cooling mode. In the left and right part of Figure 8 mild and severe conditions, respectively, can be distinguished. Since minimum temperatures were lower during the mild days, the energy charged was around $1900 \mathrm{Wh} /$ day and over, which was significantly higher than in the severe ones $(1200-1900 \mathrm{Wh} /$ day $)$. Consequently, the cold discharged by the active slab is above $400 \mathrm{Wh} /$ day in mild summer experiments and between $150 \mathrm{Wh}$ /day and $300 \mathrm{Wh}$ /day in severe summer days. 
In both severe and mild cases, the free cooling period provides higher energy supply than the cold storage sequence in all days. For mild conditions the energy obtained from free cooling oscillate between $940 \mathrm{Wh} /$ day and $1100 \mathrm{Wh} /$ day, while the severe conditions registered lower values from $420 \mathrm{Wh} /$ day to $880 \mathrm{Wh} /$ day. However, free cooling supply is not covering the cooling demand during the outside peak load period.
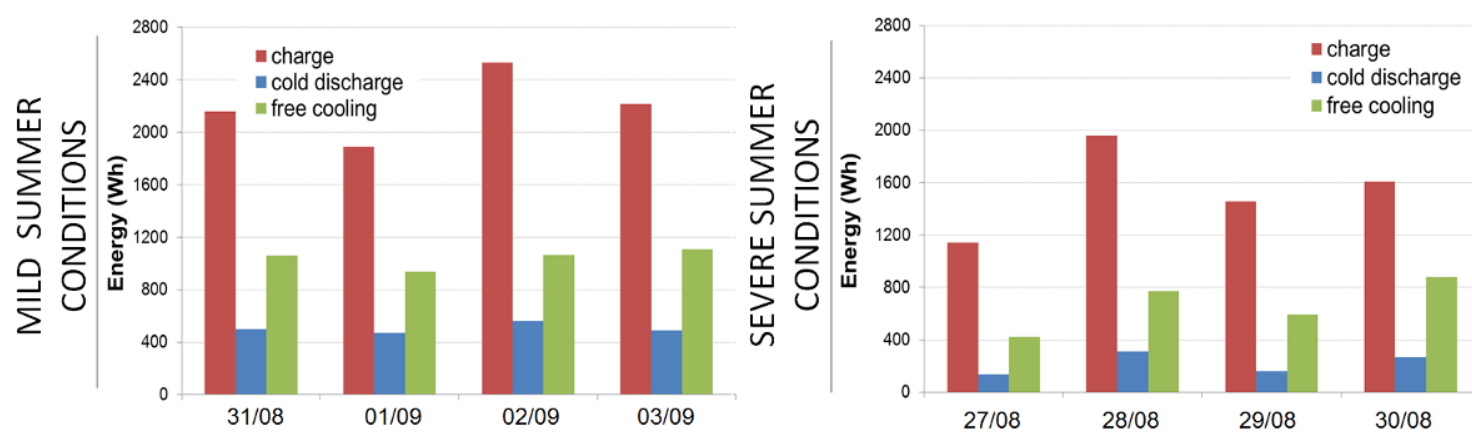

Figure 8. Cold Storage and Free Cooling experiment; charge, cold discharge and free cooling energy registered in the active slab (left: mild summer conditions, right: severe summer conditions).

\section{- $\quad$ Cold storage + Free cooling + Fans savings (CS+FC+FS)}

Some restrictions in the use of the fan, explained in section 3, were added to these experiments in order to reduce the high electrical energy consumption. Similarly to the previous tests presented $(\mathrm{CS}+\mathrm{FC})$, the experiments performed with this program (CS+FC+FS) were subjected to mild and severe summer conditions.

For the mild conditions experiments, performed from $29^{\text {th }}$ to $30^{\text {th }}$ July and $3^{\text {rd }}$ to $4^{\text {th }}$ August, the maximum and minimum outside temperatures were around $33{ }^{\circ} \mathrm{C}$ and $16{ }^{\circ} \mathrm{C}$, respectively and solar irradiance peaks of $1000 \mathrm{~W} / \mathrm{m}^{2}$ were registered. Figure 9 shows the energy charged, discharged and the free cooling one. The energy charged under mild conditions was very variable during the four days, going from $1200 \mathrm{Wh} /$ day to 2400 Wh/day. However, the cold discharged was around $500 \mathrm{Wh} /$ day in the four experiments, similarly to the results of the previous program tests (CS+FC) under mild conditions. On the other hand, the energy obtained from the free cooling was between $400 \mathrm{Wh} /$ day and $900 \mathrm{Wh} /$ day, being quite low compared with the previous experiments (CS+FC). This difference is due to the restrictions added to the use of the fan, which limit the free cooling mode to operate only when there is a cooling demand inside the cubicle, driven by the desired set point. In contrast, in the previous program (CS+FC), the free cooling mode is used when the outside temperature is lower than the internal ambient temperature, not considering the internal set point.

The experiments performed under severe conditions had maximum and minimum outside temperatures of $34{ }^{\circ} \mathrm{C}$ and $18{ }^{\circ} \mathrm{C}$, respectively, and solar irradiance peaks around $1100 \mathrm{~W} / \mathrm{m}^{2}$. The energy charged during these days, also presented in Figure 9, was 
431 about $1200 \mathrm{Wh} /$ day and due to the severe conditions the cold discharge was low 432 (around $200 \mathrm{Wh} /$ day), as well as the contribution of the free cooling sequence (less than $433200 \mathrm{Wh} /$ day).
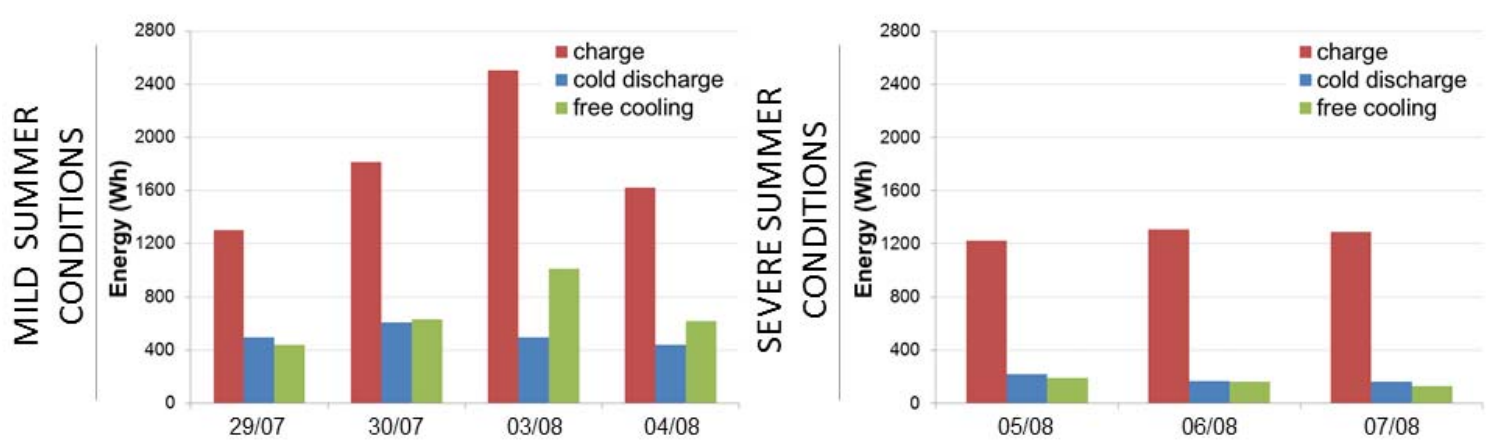

Figure 9. Cold Storage, Free Cooling, Fan Savings experiment; Charge, cold discharge and free cooling energy registered in the active slab (left: mild summer conditions, right: severe summer conditions).

\section{- $\quad$ Passive Discharge (PD)}

Moreover, passive discharge (PD) experiments were performed during $27^{\text {th }}$ and $28^{\text {th }}$ July 2014 when outside minimum temperatures during night time were around $19{ }^{\circ} \mathrm{C}$ for both days. These conditions make it difficult to solidify the PCM as it can be observed in the PCM inlet and outlet temperatures profile (Figure 10). The system cooled down the PCM during the night without achieving complete solidification. However, during the day, while the PCM is melting, the slab is providing passive cooling without the use of the fan.

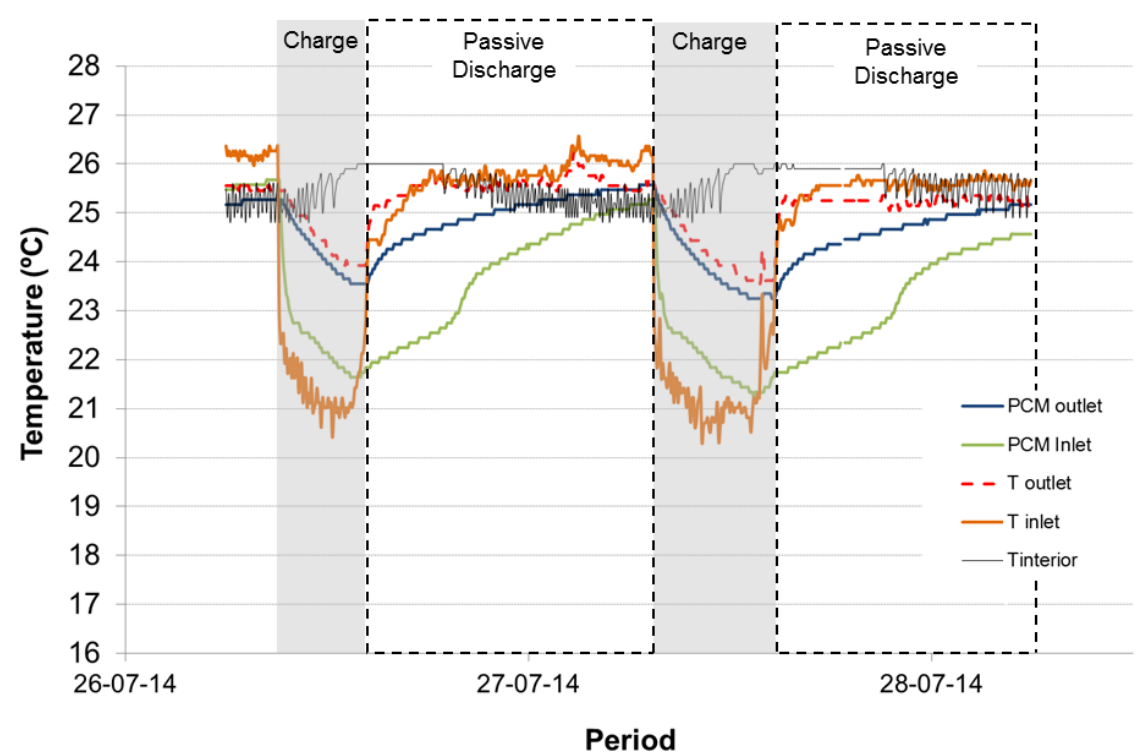

Figure 10. Passive discharge experiment; temperatures profile. 


\section{- Summary}

The energy charged and discharged for all the experiments presented in this paper is summarized in Table 1. In the case of experiments with night free cooling, the energy discharged is distinguished between cold storage and free cooling.

Table 1. Results for the analysed experiments.

\begin{tabular}{|c|c|c|c|c|}
\hline \multirow{2}{*}{ Experiment } & \multirow{2}{*}{$\begin{array}{l}\text { Weather } \\
\text { conditions }\end{array}$} & \multirow{2}{*}{$\begin{array}{c}\text { Energy Charged } \\
\text { (Wh) }\end{array}$} & \multicolumn{2}{|c|}{ Energy Discharged (Wh) } \\
\hline & & & Cold Discharged & Free cooling \\
\hline \multirow{4}{*}{ TS } & \multirow{4}{*}{ MILD } & 1630 & 825 & - \\
\hline & & 1652 & 786 & - \\
\hline & & 2060 & 692 & - \\
\hline & & 1436 & 487 & - \\
\hline \multirow{4}{*}{ CS } & \multirow{4}{*}{ MILD } & 1545 & 713 & - \\
\hline & & 1720 & 701 & - \\
\hline & & 1626 & 654 & - \\
\hline & & 2046 & 686 & - \\
\hline \multirow{4}{*}{$\mathrm{CS}+\mathrm{FC}$} & \multirow{4}{*}{ MILD } & 2158 & 501 & 1059 \\
\hline & & 1892 & 473 & 937 \\
\hline & & 2532 & 561 & 1063 \\
\hline & & 2217 & 488 & 1109 \\
\hline \multirow{4}{*}{$\mathrm{CS}+\mathrm{FC}$} & \multirow{4}{*}{ SEVERE } & 1143 & 138 & 423 \\
\hline & & 1961 & 311 & 770 \\
\hline & & 1459 & 161 & 593 \\
\hline & & 1607 & 271 & 879 \\
\hline \multirow{4}{*}{$\mathrm{CS}+\mathrm{FC}+\mathrm{FS}$} & \multirow{4}{*}{ MILD } & 1301 & 495 & 441 \\
\hline & & 1815 & 610 & 630 \\
\hline & & 2506 & 495 & 1011 \\
\hline & & 1623 & 440 & 616 \\
\hline \multirow{3}{*}{$\mathrm{CS}+\mathrm{FC}+\mathrm{FS}$} & \multirow{3}{*}{ SEVERE } & 1224 & 218 & 189 \\
\hline & & 1309 & 166 & 162 \\
\hline & & 1291 & 164 & 129 \\
\hline \multirow{2}{*}{ PD } & \multirow{2}{*}{ SEVERE } & 968 & - & - \\
\hline & & 1247 & - & - \\
\hline
\end{tabular}

462

463

464

465

466

467

468

469

470

471

472

473

474

\subsection{Active slab vs. Reference}

Although the active slab provides some cooling, the cubicle still needs the heat pump support to maintain the set point temperature $\left(25^{\circ} \mathrm{C}\right)$. Figure 11 shows the energy consumption of the heat pumps installed in the active slab and reference cubicles during the $\mathrm{CS}+\mathrm{FC}, \mathrm{CS}+\mathrm{FC}+\mathrm{FS}$, and PD experiments.

The energy consumption used for cooling both cubicles is lower under mild weather conditions ( $0.5 \mathrm{kWh} /$ day or less) compared to the energy consumed under severe conditions $(0.5 \mathrm{kWh} /$ day $-1.1 \mathrm{kWh} /$ day $)$. This fact favours the performance of the active slab system during mild weather conditions, resulting in lower energy 
consumption or even not using the heat pump in some experiments and hence, having

476 higher energy savings. However, experiments performed under severe conditions also

477 registered energy savings between $15 \%$ and $20 \%$ per day. Also notice that the active

478 slab cubicle achieved energy savings of $15 \%$ and $18 \%$ using the passive discharge 479 mode.

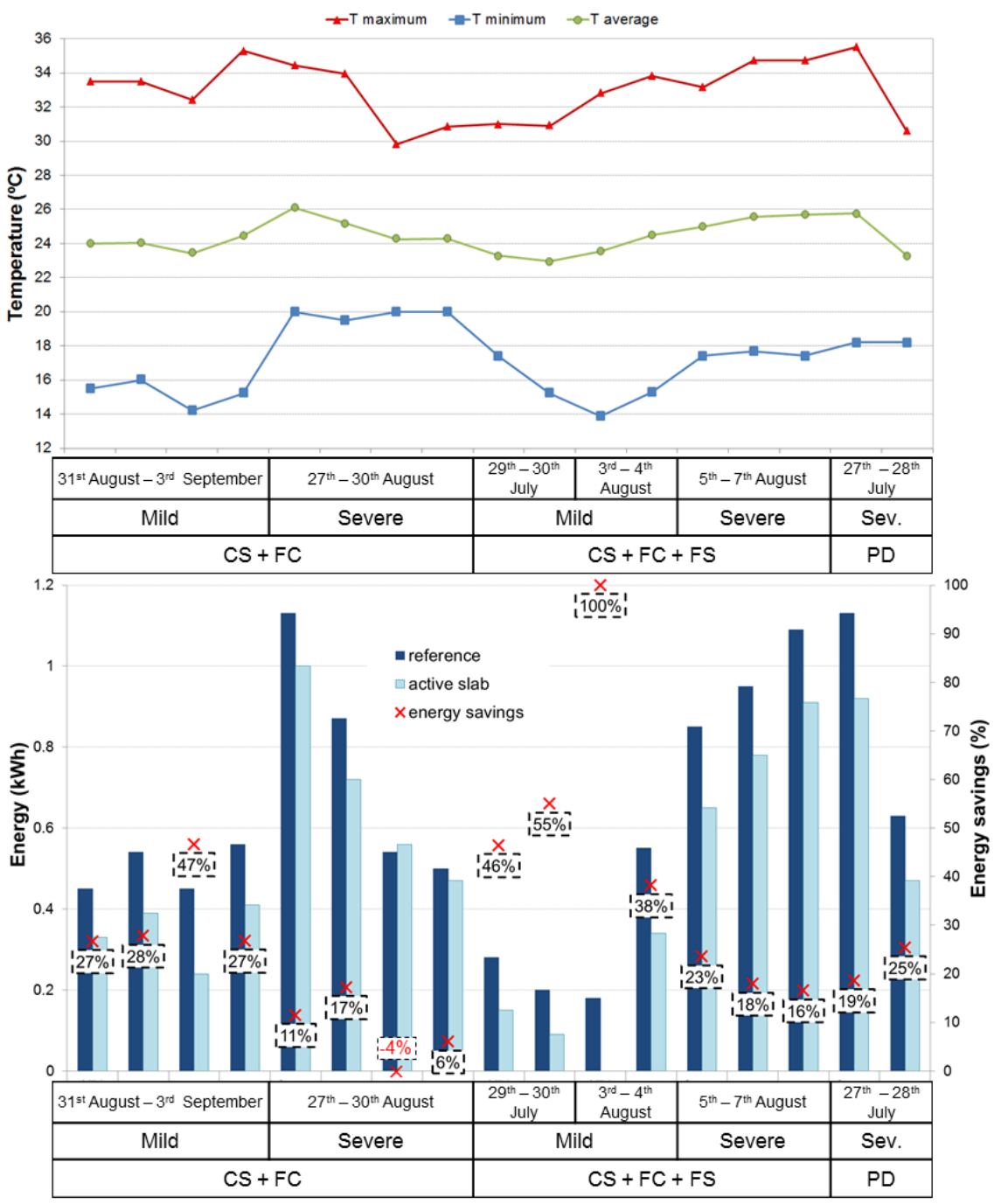

Figure 11. Daily electrical energy consumption of the heat pump of active slab and reference cubicles during $\mathrm{CS}+\mathrm{FC}, \mathrm{CS}+\mathrm{FC}+\mathrm{FS}$, and PD experiments under mild and severe summer conditions.

A trend could be observed in Figure 11 when comparing energy savings obtained in the active cubicle against minimum temperatures. For example, the third day of the CS+FC under mild conditions has a lower minimum temperature and so the energy savings obtained became higher than the other days tested. Moreover, in CS+FC+FS under mild conditions the energy savings are growing from the first day to the third one, at the same time that minimum temperatures are dropping. Therefore, some of the cases mentioned before could lead to the conclusion that active slab system efficiency is high dependent on the minimum night temperatures. Nevertheless, there are other parameters 
that could affect also the thermal performance of the system such as the maximum temperatures.

Although the active slab reduces the heat pump consumption achieving energy savings, the high energy consumed by the fan is not balanced. In the time schedule experiments (TS) the use of the fan is constant since it is time dependent, maintaining the electrical energy consumption in $1.8 \mathrm{kWh} /$ day. On the other hand, in the cold storage experiments (CS) the use of the active slab was unnecessary since the mild weather conditions did not require any cooling supply to maintain the internal ambient temperature under 25 ${ }^{\circ} \mathrm{C}$, and the fan was consuming almost $3 \mathrm{kWh} /$ day.

The electrical energy consumption of the fan is still high in the CS+FC experiments (2.1 - $2.6 \mathrm{kWh} /$ day) since free cooling mode is also using mechanical ventilation. The restrictions added in the $\mathrm{CS}+\mathrm{FC}+\mathrm{FS}$ contribute to reduce the use of the fan to 1.2 $\mathrm{kWh} /$ day in some cases.

Finally, in the passive discharge (PD) experiments the energy consumed by the fan was significantly reduced to less than $1 \mathrm{kWh}$ /day since the discharging period was done passively, but still the energy savings achieved in the active slab cubicle were not enough to balance the fan consumption.

The performance of the active slab as a cooling system is demonstrated in the experimental summer campaign presented in this paper. Nevertheless, the system should be equipped with a more efficient fan in order to be energetically efficient.

\section{Conclusions}

An innovative active slab system consisting of a prefabricated concrete slab with phase change material inside its hollows is presented in this paper as a thermal energy storage component and cooling supply system.

The implementation of the prototype in a house-like cubicle of the experimental installation at Puigverd de Lleida allows the authors to test it under real conditions. The experimental campaign was performed during summer 2014 and the results were analysed and compared to a reference cubicle with conventional cooling system.

Different operating modes were performed in the active slab cubicle: time schedule, cold storage, cold storage with free cooling, cold storage with free cooling, fans savings and set point, and passive discharge. In all the operating scenarios the active slab system showed potential to store and provide cooling supply. 
The system dependence on the outside conditions to achieve a complete charge is reflected in the energy charged during mild and severe conditions experiments, as well as the power available and required to solidify the PCM.

Time schedule experiments could be suitable for mild conditions were there is low cooling demand. However, the performance of this program could be unfavourable with severe temperatures or unpredictable conditions causing overheating in the internal ambient. This fact demonstrates that the use of an appropriate control system is required for driving these systems.

In the control temperature experiments, the cold discharged was not enough to cover the whole cooling demand of the cubicle. However, significant energy savings in the HVAC system were registered, between $30 \%$ and 55\% under mild conditions, and between $15 \%$ and $20 \%$ under severe conditions, compared to the reference cubicle.

Moreover, the potential of the free cooling mode during night time was demonstrated in order to cool down the internal ambient and keep it cooler at the beginning of the next day. This mode could be really useful for constructive systems with high thermal inertia which delays the peak temperature and resulting in high cooling demand during the evening.

In addition, the passive discharge mode should be also taken into account in this system since it could be an interesting alternative when outside temperatures at night do not drop below $21^{\circ} \mathrm{C}$.

However, the weak point of the system is the energy consumption of the fan which is critical to balance the energy savings achieved in the heat pump energy consumption. This issue could be addressed by replacing the fan with a more efficient one. Furthermore, improvements could be done in the control system programs in order to be more accurate and optimize the fan operation.

\section{Acknowledgements}

This work was supported by the "Corporación Tecnológica de Andalucía” by means of the project "MECLIDE-Soluciones estructurales con materiales especiales para la climatización diferida de edificios" with the collaboration of DETEA. The work partially funded by the Spanish government (ENE2011-28269-C03-01 and ULLE104E-1305). The authors would like to thank the Catalan Government for the quality accreditation given to their research group (2014 SGR 123) and the city hall of Puigverd de Lleida. The research leading to these results has received funding from the European Union's Seventh Framework Programme (FP7/2007-2013) under grant agreement $n^{\circ}$ PIRSES-GA-2013-610692 (INNOSTORAGE). Alvaro de Gracia would like to thank Education Ministry of Chile for Grant PMI ANT1201. 


\section{References}

1. Directive 2010/31/EU of the European parliament and of the council of 19 May 2010 on the energy performance of buildings. Available from: http://www.epbdca.eu.

2. KaKac S, Paykoc E, and Yener Y. Storage of solar thermal energy. In: Kilkis B and Kakac S (eds.) NATO ASI Series, Series E: Applied Sciences, Vol. 167: Energy Storage Systems, Dordrecht: Kluwer Academic Publishers; 1989, pp. 129-161.

3. Basecq V, Michaux G, Inard C, Blondeau P. Short-term storage systems of thermal energy for buildings: a review. Advances in Building Energy Research 2013;7(1):66-119.

4. Dincer I., Rosen M.A., 2002. Thermal Energy Storage, Systems and Application. In: John Wiley \& Sons (eds.), Chichester, United Kingdom.

5. Navarro L, de Gracia A, Niall D, Castell A, Browne M, McCormack S.J., Griffiths P., Cabeza L.F. Thermal energy storage in building integrated thermal systems: A review. Part 2. Integration as passive system. Renewable Energy, 2015 in press. DOI: 10.1016/j.renene.2015.06.064.

6. Solar energy systems in architecture, integration criteria and guidelines 2012, Report T.41.A.2: IEA SHC Task 41 Solar energy and Architecture. Available from: http://task41.iea-shc.org/ (September 2014).

7. Navarro L, de Gracia A, Colclough S, Browne M, McCormack S.J., Griffiths P., Cabeza L.F. Thermal energy storage in building integrated thermal systems: A review. Part 1. Integration as active system. Renewable Energy, 2015 in press.

8. Garg, H.P., Mullick, S.C., Bhargava, A.K, 1985. Solar Thermal Energy Storage. In: D. Reidel Publishing Company, Dordrecht, Holland.

9. Heier J, Bales C, Martin V. Combining thermal energy storage with buildings - a review. Renewable and Sustainable Energy Reviews 2015;42:1305-25.

10. Cabeza LF, Castell A, Barreneche C, de Gracia A, Fernández AI. Materials used as PCM in thermal energy storage in buildings: A review. Renewable and Sustainable Energy Reviews 2011;15:1675-95.

11. Zhou D, Zhao CY, Tian Y. Review on thermal energy storage with phase change materials (PCMs) in building applications. Applied Energy 2012;92:593-605. 
12. Barton P, Beggs CB, Sleigh PA. A theoretical study of the thermal performance of the TermoDeck hollow core slab system. Applied Thermal Engineering 2002;22:1485-99.

13. Pomianowski M, Heiselberg P, Jensen RL. Dynamic heat storage and cooling capacity of a concrete deck with PCM and thermally activated building system. Energy and Buildings 2012;53:96-107.

14. Non-residential cooling and heating load calculations. In: Parsons RA, editor. Ashrae Handbook Fundamentals, Atlanta: American Society of Heating, Refrigerating and Air-Conditioning Engineers, Inc.; 1997, p.28.7-28.16.

15. Navarro L, De Gracia A, Castell A, Álvarez S, Cabeza LF. PCM incorporation in a concrete core slab as a thermal storage and supply system: proof of concept. Energy and Buildings 2015;103:70-82.

16. De Gracia A, Navarro L, Castell A, Ruiz-Pardo A, Álvarez S, Cabeza LF. Thermal analysis of a ventilated facade with PCM for cooling applications. Energy and Buildings 2013;65:508-15. 